\title{
Special feature: workshop on random system solution of the transformation problem: discussion with Prof. Bertram Schefold
}

\author{
Kiichiro Yagi ${ }^{1}$
}

Published online: 20 September 2019

(C) Japan Association for Evolutionary Economics 2019

The theoretical problem of the consistency between labor theory of value and the price formation with a general rate of profit (production price) in Marxian economics is called "Transformation Problem." According to the concept of exploitation based on the labor theory of value, those industries that employ larger numbers of workers acquire more surplus value than those of smaller numbers of workers. However, under the condition of the free movement of capital, the same amount of capital has to receive the same amount of profit without difference among industries. Thus, to prove the exploitation under capitalism, value and surplus value in the first volume of Marx's Capital have to transform themselves to production price and profit.

In 1885, when the second volume of Capital was published posthumously, the editor, Marx's close friend Friedrich Engels, challenged all the ambitious theoreticians "in which way an equal average rate of profit can and must come about, not only without a violation of the law of value, but on the very basis of it." 1 After 9 years, Engels could publish the third volume of Capital that contains Marx's solution. However, it did not cease the debate, because Marx's transformation remained at the first step that the total surplus value is distributed to capital according to the general rate of profit counted on the value term. Thus, this debate has the long history that surpassed well over a century.

At present, at least in the mathematical analysis, we need not worry about the ethical connotation of "exploitation." It indicates the state of distribution in each level of value or price system. Modern debates on capital taught us that price system, consequently the value of capital too, is not independent of the distribution. Thus, "transformation problem" is located close to the core of classical and modern theory of price and capital.

\footnotetext{
1 Karl Marx, Capital vol 2, Moscow: Progress Publisher, 1967, p 19.
}

Kiichiro Yagi

yagi@econ.setsunan.ac.jp

1 Setsunan University, Neyagawa-shi, Osaka-fu, Japan 
On December 21, 2018, a small workshop was held at the Surugadai Centennial Hall of Chuo University, Tokyo. The topic is the examination of the new solution of "transformation problem" using random input matrices by Professor Bertram Schefold. He came to Tokyo to attend the International Symposium of the 200th Anniversary of the Birth of Marx, December 22-23, Tokyo. The workshop was arranged separately for the discussion of the limited circle of specialists on Schefold's new solution. The organizer distributed Schefold's 2016 article ("Profits Equal Surplus Value on Average and the Significance of this Result for the Marxian Theory of Accumulation," Cambridge Journal of Economics, vol 40, pp 165-199) to the participants in advance. Later, Prof. Schefold's conference paper, "The Transformation of Values into Prices on the Basis of Random Systems Revisited," was also delivered. Four notes were presented, but as one of them did not deal with Schefold's solution, the main discussions were those between three note presenters and Prof. Schefold. Though authors of the notes presented were not fully convinced by this random system solution, all of them admitted the value of this new solution. At the closing of the workshop, the organizer asked Prof. Schefold and authors of three notes to revise their contributions and submit after a half year for the special issue in the Evolutionary and Institutional Economics Review.

As the organizer of the workshop and the associate editor of this special feature in this review, I appreciate the authors and Prof. Yuji Aruka, Chuo University, who helped me in the arrangement of the workshop as well as in the theoretical discussion there.

Publisher's Note Springer Nature remains neutral with regard to jurisdictional claims in published maps and institutional affiliations. 